
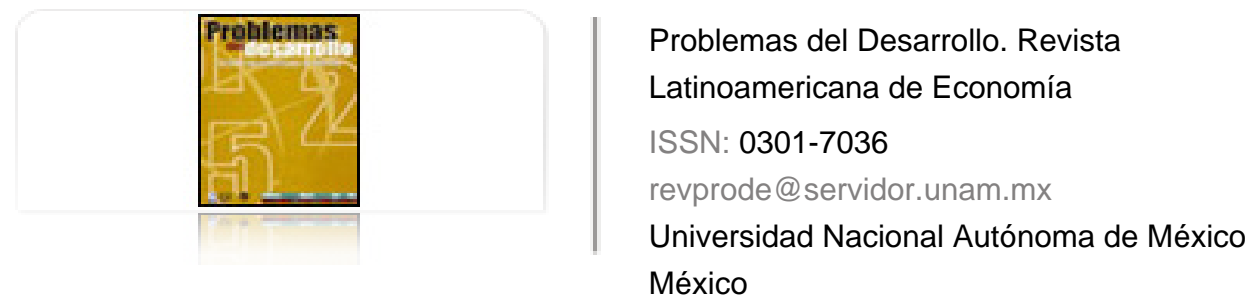

Alarco Tosoni, Germán

Reforma estructural en la integración de la industria maquiladora a la economía mexicana Problemas del Desarrollo. Revista Latinoamericana de Economía, vol. 37, núm. 145, abril-junio, 2006 , pp. $53-80$

Universidad Nacional Autónoma de México

Distrito Federal, México

Disponible en: http://www.redalyc.org/articulo.oa?id=11820086004

Cómo citar el artículo

- Número completo

- Más información del artículo

Página de la revista en redalyc.org

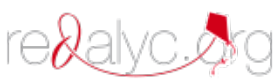

Sistema de Información Científica

Red de Revistas Científicas de América Latina, el Caribe, España y Portugal Proyecto académico sin fines de lucro, desarrollado bajo la iniciativa de acceso abierto 


\section{REFORMA ESTRUCTURAL EN LA INTEGRACIÓN DE LA INDUSTRIA MAQUILADORA A LA ECONOMÍA MEXICANA}

\section{Germán Alarco Tosoni*}

Fecha de recepción: 25 de agosto de 2005. Fecha de aceptación: 18 de abril de 2006.

\section{Resumen}

Se examina la literatura e información estadística reciente en torno al desempeño macroeconómico de la industria maquiladora en México, y se determina su contribución actual a la balanza de pagos, empleo, remuneraciones, valor agregado y al crecimiento económico. La aportación de esa actividad al crecimiento económico es ahora reducida, pero puede ser más significativa si se modifican sus parámetros estructurales y de la economía: la propensión de la industria maquiladora a importar insumos (recíproca a la suma del componente de insumos nacionales y la aportación al valor agregado), el componente importado de la formación bruta de capital, la propensión media a importar del resto de actividades y la estructura de la distribución del ingreso. Se esbozan las políticas que podrían diseñarse y aplicarse para mejorar la articulación de ese sector con el resto de las actividades productivas.

Palabras clave: maquila, encadenamientos, integración, reformas y macroeconomía

\section{Abstract}

The recent literature and statistical information on the macroeconomic performance of Mexico's maquiladora industry is examined, and its present contribution to the balance of payments, employment, remunerations, aggregate value and economic growth is determined. The contribution of this activity to economic growth is now limited, although it may be more significant if its structural and economic parameters are modified: the propensity of the maquiladora industry to import inputs (reciprocal to the sum of the national input component and the contribution to aggregate value), the imported component of gross capital formation, the other activities' average propensity to import, and the structure of income distribution. Policies are sketched that could be designed and applied to improve the articulation of that sector with the rest of the productive activities.

Key words: maquiladora, chaining, integration, reforms and macro-economy.

\footnotetext{
* Profesor de la Universidad Panamericana, ciudad de México. Correo electrónico: germanalarco@yahoo.com.mx. El autor agradece los valiosos comentarios de Patricia Del Hierro Carrillo y de los dictaminadores anónimos de la revista que permitieron enriquecer el contenio del documento. También resaltamos el valioso apoyo de Rafael Hernández Parra en el trabajo estadístico y econométrico incorporado en el estudio.
} 


\section{Résumé}

On examine la littérature et l'information statistique récente autour du rendement macroéconomique de l'industrie de sous-traitance au Mexique et on détermine sa contribution actuelle à la balance des paiements, des emplois, des rémunérations, de la valeur ajoutée et de la croissance économique. L'apport de cette activité à la croissance économique est actuellement réduit, mais il pourrait être plus significatif si on modifie ses paramètres structuraux et ceux de l'économie : la propension de l'industrie de sous-traitance à importer des facteurs de production (réciproque à la somme du composant des facteurs de production nationaux et à l'apport de la valeur ajoutée), le composant importé de la formation brute de capital, la propension moyenne à importer du reste des activités et la structure de la distribution des revenus. On ébauche les politiques qui pourraient être conçues et appliquées pour améliorer l'articulation de ce secteur avec le reste des activités productives.

Mots-cléfs: sous-traitance, enchaînements, intégration, réformes et macroéconomie.

\section{Resumo}

Examina-se a literatura e informações estatísticas recentes sobre o desempenho macroeconômico da indústria maquiadora no México e se determina sua contribuição atual à balança de pagos, empregos, remunerações valor agregado e ao crescimento econômico. A aportação de essa atividade para o crescimento econômico é agora reduzida, porém pode ser mais significativa se modificassem os seus parâmetros estruturais e da economia: a proclividade da indústria maquiadora a importar insumos (recíproca à soma do componente de insumos nacionais e a aportação ao valor agregado), o componente importado da formação bruta de capital, a propensão média a importar do resto de atividades e a estrutura da distribuição do ingresso. Se prevêm as políticas que poderiam desenhar-se e aplicar-se para o melhoramento da articulação desse setor com o resto das atividades produtivas.

Palavras chave: maquia, encadenamentos, integração, reformas e macroeconomia

\section{DeSarrollo}




\section{Introducción}

a industria maquiladora en México es una realidad de cuatro décadas de existencia. Es evidente su contribución a la generación de divisas y al empleo, pero también

es claro que la articulación de ésta respecto a la economía nacional es muy reducida. La modificación de la naturaleza y el aumento de la magnitud de esta vinculación es esencial por sus probables efectos dinamizadores sobre el conjunto de la economía, más de lo que podría ocurrir con la implantación de otras políticas como las denominadas reformas estructurales: energética, fiscal y laboral.

Los objetivos de este artículo son múltiples. Se trata, en primer lugar, de realizar un balance de las contribuciones macroeconómicas de la actividad maquiladora en México, en las variables tradicionales y con la información más reciente tanto en el nivel conceptual como a partir de la información estadística disponible. En segundo lugar, seleccionar sus componentes principales y evaluar su aportación al crecimiento económico tanto en una perspectiva internacional comparada como mediante un modelo macroeconómico ad hoc para la economía mexicana. La hipótesis central es que existe un amplio margen de maniobra para incrementar las articulaciones entre el sector maquilador y el resto del aparato productivo, que de concretarse implicaría importantes efectos positivos en toda la economía.

En lo formal, el artículo tiene cinco secciones. En la primera se revisa brevemente la literatura concerniente a los aspectos macroeconómicos de la industria maquiladora. En la segunda se examina la información estadística de esa actividad en cuanto a su contribución a la economía nacional y el detalle de sus principales características. En la tercera se evalúa la contribución de las exportaciones al crecimiento económico en una perspectiva internacional comparada. En la cuarta se formula un modelo macroeconómico básico para evaluar la contribución de la industria maquiladora al producto y crecimiento de la economía nacional; se realizan diversos ejercicios relativos a una mayor integración de la maquila y dichos resultados se comparan con los que se generarían al implantar reformas estructurales. Por último, se esboza un conjunto de políticas para mejorar la articulación de la industria maquiladora a la economía nacional.

En este documento no se aborda la problemática de la producción sectorial y regional o por entidades federativas y municipales de la industria maquiladora. No se analizan los aspectos microeconómicos de la actividad maquiladora ni la probable contribución de dicha actividad a la endogenización del cambio técnico. Tampoco se presentan ni discuten los determinantes y las políticas instituidas que hacen posible la maquiladora ni los regímenes particulares de tratamiento a las exportaciones e importaciones en las zonas fronterizas.

\section{DeSarrollo}


No se analiza su tendencia o perspectivas para el corto, mediano y largo plazos. Las alusiones a las denominadas reformas estructurales energética, fiscal y laboral son marginales, ya que no se discute la naturaleza detallada de las mismas y nos circunscribimos a evaluar el impacto comparativo de algunas de éstas en relación con la industria maquiladora. La articulación detallada de las propuestas de políticas para promover la mayor integración de la industria maquiladora requiere de un análisis pormenorizado que no es materia de este artículo.

Es importante comentar que el modelo macroeconómico propuesto es agregado, de naturaleza keynesiana-poskeynesiana. En éste, el producto es determinado por la demanda, los factores distributivos son importantes para el nivel de actividad económica y los precios son fijos, razón por la cual una modificación en el nivel o componente nacional de las exportaciones de la industria maquiladora no genera efecto alguno en el nivel de precios de la economía.

\section{Maquila y análisis macroeconómico}

La actividad maquiladora en México se inició formalmente en 1965 con el Programa Nacional Fronterizo, tanto por las necesidades económicas y sociales de hacer frente a la finalización unilateral por parte de los Estados Unidos de América (EUA) del Acuerdo Internacional sobre Trabajadores Migratorios en $1964,{ }^{1}$ como por la influencia de los resultados de un estudio específico encargado a la firma Arthur D. Little en el mismo año, en el cual se recomendaba la producción compartida con un tratamiento aduanal preferencial y la promoción de "plantas gemelas". ${ }^{2}$ El siguiente hito fue el establecimiento en 1971 y 1972 de la reglamentación y las primeras modificaciones al artículo 321 del Código Aduanero, que integraban diversas circulares y resoluciones para normar la actividad. Durante el gobierno de López Portillo se establecieron las terceras modificaciones al citado reglamento, mediante las cuales se buscaba, entre otras cosas, que la maquila incluyese como mínimo $20 \%$ de contenido nacional mexicano en los productos de exportación; se le autorizó de igual manera realizar directamente sus trámites aduanales. ${ }^{3}$

En 1983 se dictó el Decreto para el Fomento y Operación de la Industria maquiladora de Exportación, seguido por las modificaciones de 1989, 1996 y 1998, que permitían la colocación de mayor porcentaje de su producción en el mercado interno; se creó la modalidad de los Programas de Importación Temporal, y se redujeron sustancialmente los trámites a los que estaba sometida la actividad. ${ }^{4}$ Por último, el Tratado de Libre Comercio de América del Norte (TLCAN) estableció las bases para una mayor integración productiva y comercial

R. Buitelaar, R. Padilla y R. Urrutia, "Industria maquiladora y cambio técnico", en Revista de la CEPAL, núm. 67, abril de 1999, p. 139.

2 G. Mendiola, "México: empresas maquiladoras de exportación en los noventa", en Serie Reformas Económicas 49, CEPAL, diciembre de 1999, pp. 7 8.

3 Ibidem, pp. 9 10.

$4 \quad$ Ibidem, pp. 11 13.

\section{DeSarrollo}


de las maquiladoras, pero eliminaba a mediano plazo el trato particular al que se encontraban sometidas.

Las Naciones Unidas-CEPAL ${ }^{5}$ presentan un balance de la actividad maquiladora, con sus diversas variantes a nivel regional, que resulta interesante como punto de partida para evaluar la problemática mexicana. Se sostiene que dicha industria estimula las ventas externas (el ingreso neto de divisas), promueve la absorción de mano de obra, atrae inversión extranjera directa, apoya la internacionalización del progreso técnico, crea posibilidades de calificación-perfeccionamiento de la mano de obra y de la gestión empresarial e impulsa vínculos con las empresas locales orientadas tradicionalmente al mercado interno. Sin embargo, comentan que es preciso considerar que las exportaciones netas son bastante menores que las exportaciones brutas, debido a la gran proporción del componente importado. La infraestructura que exige la instalación y operación de estas plantas eleva el costo por empleo generado. La internalización del progreso técnico puede frenarse si se limita a actividades de ensamblaje, en las cuales los insumos nacionales y el valor agregado son mínimos. Por otra parte, puede haber un costo fiscal tanto por los "subsidios" necesarios para promoverla como por los menores ingresos fiscales que implica, y la maquila puede ser temporal si se promueve a partir de costos salariales reducidos sin tomar en cuenta una noción de competitividad sistémica. ${ }^{6}$

Villarreal y Ramos de Villarreal señalan que a nivel nacional la principal característica del sector exportador es la desarticulación de las cadenas productivas y, por ello, la industria maquiladora tiene poco arrastre y por sí sola sería incapaz de generar los empleos necesarios para un crecimiento dinámico y sustentable. ${ }^{7}$ Mendoza y Calderón ${ }^{8}$ coinciden en señalar que la industria maquiladora se caracteriza por ser un enclave productivo exportador con un limitado encadenamiento productivo hacia atrás y nulo hacia delante, por lo que su vinculación real con la economía nacional se realiza por medio del mercado laboral y los ingresos de divisas. Carrillo y Gomis ${ }^{9}$ coinciden en señalar el escaso desarrollo de proveedores locales (la integración nacional sería alrededor de 2\%) y el deterioro ambiental, ya que $60 \%$ de las empresas no reexporta sus desechos tóxicos. Puyana y Romero ${ }^{10}$

5 Naciones Unidas CEPAL, América Latina y el Caribe, Políticas para mejorar la inserción a la economía mundial, Santiago de Chile, 1994, pp. 123 133.

6 Naciones Unidas CEPAL, op. cit., pp. 126 132.

7 R. Villarreal y R. Ramos de Villarreal, "La apertura de México y la paradoja de la competitividad: hacia un modelo de competitividad sistémica", en Comercio Exterior, México, BANCOMEXT, septiembre de 2001, p. 777.

8 E. Mendoza y C. Calderón, "Determinantes regionales de la maquila de exportación en la frontera norte", en Comercio Exterior, México, BANCOMEXT, marzo de 2001, p. 197.

9 J. Carrillo y R. Gomis, "Los retos de las maquiladoras ante la pérdida de la competitividad", en Comercio Exterior, vol. 53, núm. 4, México, BANCOMEXT, abril de 2003, p.318.

10 A. Puyana y J.A. Romero, "La maquila (fragmentación de los procesos productivos) y su impacto sobre las remuneraciones a los factores", en Problemas del Desarrollo, vol. 36, núm. 141, México, UNAM, abril junio 2005, p. 176. 
concuerdan en que dicha industria no ha desarrollado encadenamientos ni nexos con el resto de las actividades económicas.

Los diferentes investigadores coinciden en señalar los impactos positivos de la industria maquiladora en la generación de empleo. Sin embargo, hay divergencia en cuanto a su papel en las estrategias de desarrollo, ya que para algunos puede ser base del desarrollo, siempre que se apoye en mano de obra barata no parece compatible con una estrategia de largo plazo de crecimiento con equidad. ${ }^{11}$ En esta dirección, la maquila, en su forma actual, no parece ser el motor del desarrollo sustentable con equidad, aunque su contribución es positiva si se toma en cuenta la generación de empleo. Puyana y Romero ${ }^{12}$ señalan que el elevado crecimiento de las exportaciones no tiene incrementos paralelos en el valor agregado y en la productividad. Asimismo, algunos investigadores que analizan la experiencia en Matamoros comentan que esta actividad ha tenido elevados costos sociales al acompañarse de un inadecuado ordenamiento del espacio urbano que afecta la calidad de vida de los trabajadores, una elevada inestabilidad laboral y diferentes tipos de prestaciones laborales hacia la baja. ${ }^{13}$

El camino por seguir sería entonces transformarla en una actividad que no sólo base su competitividad en los salarios bajos y en las condiciones de acceso privilegiado al mercado, sino también en aumentos de la productividad y del contenido del valor agregado. ${ }^{14}$ Fujji y Gaona, ${ }^{15}$ en su análisis de las políticas para el crecimiento económico implantadas por el gobierno del Presidente Fox, señalan que existe un obstáculo al incremento del empleo y los salarios por el papel que el sector maquilador de exportación desempeña en la economía nacional, ya que éste comprime la demanda interna y el crecimiento. La estrategia de crecimiento basada en la exportación maquiladora vinculada exclusivamente al desempeño de la economía de Estados Unidos y a la exportación de seres humanos (braceros) exige que los costos laborales unitarios no se eleven, ya que podría perderse competitividad. Por lo anterior, el límite al incremento de los salarios reales está dado por la dinámica de la productividad laboral en la maquila. Los salarios en la maquila no pueden ser sistemáticamente inferiores a los del resto de la economía, ya que esto provocaría el desplazamiento de mano de obra de una actividad a otra. ${ }^{16}$

11 R. Buitelaar, R. Padilla y R. Urrutia, op. cit., p. 149.

12 A. Puyana y J.A. Romero, op. cit., pp. 181.

13 C. Quintero, Los claroscuros de la industria maquiladora: los casos de Tijuana y Matamoros, documento El Colegio de la Frontera Norte, Dirección Regional de Matamoros, septiembre de 2003, pp. 12 32.

14 R. Buitelaar, R. Padilla y R. Urrutia, op. cit., p. 149.

15 G. Fujii y C. Gaona, "El modelo maquilador como barrera al crecimiento del empleo y los salarios en México", en Economía Informa, núm. 323, México, unAM, febrero de 2004, pp. 63 64.

16 Ibidem, pp. 69 70.

\section{DeSarrollo}


La base del razonamiento anterior se encuentra en Fujii, Candaudap y Gaona, ${ }^{17}$ que plantean que las remuneraciones-salarios de las maquiladoras y de la manufactura tradicional se correlacionan y que, aunque se determinan mutuamente, los del sector maquilador influyen de manera muy importante en la determinación de los del resto de la manufactura. Lo anterior significa que en la medida que los bajos salarios relativos de la maquila constituyan una de las bases de su competitividad, presionarán hacia la baja el salario del resto de la manufactura. Sólo si se va consolidando el tránsito hacia una competitividad de la industria maquiladora cada vez más asentada en el aumento de la productividad, las remuneraciones del conjunto de la economía podrían elevarse. La opción elegida por el país - basar sus exportaciones en la industria maquiladora con productividad estancadapresenta el enorme peligro de que los nuevos países que se están integrando al comercio internacional con salarios más reducidos (por ejemplo, China, cuando los medimos en us\$ corrientes) vayan siendo más competitivos, lo que obliga a mantenerlos comprimidos en México para no perder competitividad. ${ }^{18}$

Un tema relevante que tenemos que comentar es que la industria maquiladora mexicana no es un todo homogéneo. Esto en relación a que se han desarrollado estereotipos que las satanizan o que las convierten en una panacea. ${ }^{19}$ No son un sector productivo ni conforman un único modelo de organización industrial, de forma de empleo, de nivel tecnológico, de trayectorias de aprendizaje y de culturas corporativas. Son un conjunto heterogéneo en el que coexisten trayectorias productivas disímiles. Las tipologías para clasificarlas son diversas, aunque particularmente nos atrae la de Carrillo y Hualde, ${ }^{20}$ que la dividen en tres generaciones de empresas según estén basadas en la intensificación del trabajo manual, en la racionalización del trabajo o en el aprovechamiento intensivo del conocimiento. La industria maquiladora es un complejo enjambre de relaciones entre firmas, empresas, instituciones, actores y regiones, en el cual las trayectorias de aprendizaje y las generaciones socio-técnicas en la atención a los productos y a las ramas productivas involucradas son centrales en el análisis. ${ }^{21}$

\section{La maquila mexicana en el tiempo}

Las principales variables de la industria maquiladora que pudieran tener implicaciones de carácter macroeconómico se muestran en el Cuadro 1. En primer lugar, destacan las

17 G. Fujii, E. Candaudap y C. Gaona, "Salarios, productividad y competitividad de la industria manufacturera mexicana", en Comercio Exterior, vol. 55, núm. 1, México, BANCOMEXT, enero de 2005, p. 28.

18 G. Fujii y C. Gaona, op. cit., p. 71.

19 J. Alonso, J. Carrillo y O. Contreras, Trayectorias tecnológicas en empresas maquiladoras asiáticas y americanas en México, Serie desarrollo productivo 72, Santiago de Chile, CEPAL, agosto de 2000, p. 35.

20 Op. cit., pp. 15 20.

21 Ibidem, p. 36.

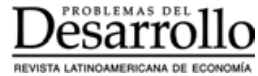


Cuadro 1

Principales indicadores de la industria maquiladora de exportación 1980-2004 millones de us\$, millones de pesos constantes de 2002 y promedio de trabajadores

\begin{tabular}{|c|c|c|c|c|c|}
\hline Año & $\begin{array}{l}\text { Exportaciones } \\
\text { (millones de US\$) }\end{array}$ & $\begin{array}{l}\text { Importaciones } \\
\text { (millones de us\$) }\end{array}$ & $\begin{array}{c}\text { Valor } \\
\text { agregado e } \\
\text { insumos } \\
\text { nacionales (millones } \\
\text { de pesos 2002) }\end{array}$ & $\begin{array}{c}\text { Remuneraciones } \\
\text { pagadas } \\
\text { (millones } \\
\text { de pesos 2002) }\end{array}$ & $\begin{array}{l}\text { Empleo } \\
\text { (promedio de } \\
\text { trabajadores) }\end{array}$ \\
\hline 1980 & 2.519 & 1.747 & 160.1 & 94.9 & 119546 \\
\hline 1981 & 3.205 & 2.229 & 169.0 & 103.5 & 130973 \\
\hline 1982 & 2.826 & 1.974 & 213.6 & 109.0 & 127048 \\
\hline 1983 & 3.641 & 2.823 & 216.3 & 103.3 & 150867 \\
\hline 1984 & 4.904 & 3.749 & 258.0 & 134.0 & 199684 \\
\hline 1985 & 5.093 & 3.826 & 274.6 & 141.5 & 211968 \\
\hline 1986 & 5.646 & 4.351 & 357.9 & 163.1 & 249833 \\
\hline 1987 & 7.105 & 5.507 & 431.0 & 202.7 & 305253 \\
\hline 1988 & 10.146 & 7.808 & 484.3 & 234.4 & 369489 \\
\hline 1989 & 12.329 & 9.328 & 561.4 & 284.4 & 418532 \\
\hline 1990 & 13.873 & 10.321 & 599.2 & 309.7 & $\begin{array}{lll}451 & 169\end{array}$ \\
\hline 1991 & 15.833 & 11.782 & 598.9 & 293.4 & 434109 \\
\hline 1992 & 18.680 & 13.937 & 622.1 & 345.1 & 503689 \\
\hline 1993 & 21.853 & 16.443 & 650.8 & 360.0 & 526351 \\
\hline 1994 & 26.269 & 20.466 & 706.9 & 399.1 & 562334 \\
\hline 1995 & 31.103 & 26.179 & 845.1 & 416.3 & 621930 \\
\hline 1996 & 36.920 & 30.505 & 970.2 & 475.7 & 748262 \\
\hline 1997 & 45.166 & 36.332 & 1153.9 & 580.4 & 903736 \\
\hline 1998 & 53.083 & 42.547 & 1388.2 & 678.5 & 1014023 \\
\hline 1999 & 63.854 & 50.409 & 1569.0 & 786.5 & 1143499 \\
\hline 2000 & 79.467 & 61.709 & 1871.6 & 949.9 & 1291498 \\
\hline 2001 & 76.881 & 57.599 & 1887.8 & 946.9 & 1202954 \\
\hline 2002 & 78.098 & 59.296 & 1811.4 & 878.7 & 1071467 \\
\hline 2003 & 77.467 & 59.057 & 1895.2 & 873.8 & 1069172 \\
\hline $2004^{\mathrm{P}}$ & 86.952 & 67.742 & 1976.3 & 916.2 & 1115230 \\
\hline
\end{tabular}

Nota: la información antes de 1990 es de Nacional Financiera, s.N.C. El valor agregado a partir de 1990 tiene ligeros ajustes respecto de la información original debido a las diferencias en el tipo de cambio promedio aplicado a las exportaciones.

Fuente: elaboración propia con base en INEGI y Nacional Financiera, S.N.C., La economía mexicana en cifras 1995, México, 1996.

exportaciones e importaciones por su contribución a la balanza de pagos y al producto, que en todo el periodo analizado crecieron a una tasa promedio anual de 15.9 y $16.5 \%$ respectivamente. Considerando dos subperiodos, 1980-1990 y 1990-2004, se observa, en contra de lo que tradicionalmente podría pensarse, que las exportaciones crecieron más en el primero de éstos, con una tasa de $18.6 \%$ anual respecto de $14 \%$ del segundo. En el caso de las importaciones, las tasas de crecimiento promedio anual fueron de 19.4 y $14.4 \%$ en el primer y segundo subperiodos. Las otras variables en importancia son el valor agregado (remuneraciones y utilidades) y los insumos nacionales incorporados en la producciónexportaciones de la industria maquiladora. También se presenta la información relativa a 
Cuadro 2

Contribución de la industria maquiladora a la economía nacional 1980-2003 (\%)

\begin{tabular}{ccccc}
\hline Años & $\begin{array}{c}\text { Exportaciones maquilal } \\
\text { Exportaciones totales }\end{array}$ & $\begin{array}{c}\text { PIB maquilal } \\
\text { PIB total }\end{array}$ & $\begin{array}{c}\text { Remuneraciones maquilal } \\
\text { Remuneraciones totales }\end{array}$ & $\begin{array}{c}\text { Empleo maquilal } \\
\text { Empleo total }\end{array}$ \\
\hline 1980 & 13.97 & 1.29 & 0.65 & 0.59 \\
1985 & 19.04 & 2.77 & 1.23 & 0.97 \\
1990 & 34.08 & 5.27 & 2.36 & 1.74 \\
1991 & 37.09 & 5.04 & 2.05 & 1.62 \\
1992 & 40.44 & 5.14 & 2.20 & 1.85 \\
1993 & 42.12 & 5.43 & 2.14 & 1.92 \\
1994 & 43.15 & 6.21 & 2.20 & 2.00 \\
1995 & 39.10 & 10.57 & 2.73 & 2.27 \\
1996 & 38.46 & 11.12 & 3.28 & 3.65 \\
1997 & 40.90 & 11.27 & 3.74 & 3.31 \\
1998 & 45.19 & 12.68 & 3.99 & 3.65 \\
1999 & 46.82 & 13.27 & 4.35 & 4.03 \\
2000 & 47.74 & 13.69 & 4.96 & 3.78 \\
2001 & 48.52 & 12.36 & 4.78 & 3.40 \\
2002 & 48.58 & 12.07 & 4.32 & 3.37 \\
2003 & 46.97 & 12.16 & 4.19 & \\
\hline
\end{tabular}

Nota: la información del producto interno bruto, remuneraciones y empleo antes de 1990 corresponde a datos obtenidos de Nacional Financiera, S.N.C.

Fuente: elaboración propia con base en INEGI y Nacional Financiera, S.N.C., La economía mexicana en cifras 1995, México, 1996.

los empleos directos, que muestra una tasa de crecimiento promedio anual de $9.8 \%$, en la cual en el primer subperiodo fue de $14.2 \%$, mientras en el segundo de $6.7 \%$ promedio anual, muy por debajo del dinamismo observado en las exportaciones.

La contribución de la industria maquiladora a la economía nacional se determina expresando cada una de esas variables respecto de las observadas para los mismos años a nivel nacional, tal como se muestra en el Cuadro 2. Las exportaciones de dicha industria van de representar poco menos de $14 \%$ en 1980 a conformar $47 \%$ del total de las exportaciones en 2004. La participación en el producto se ha multiplicado más de nueve veces, de 1.3 a $12.2 \%$ del producto interno bruto (PIB). Si bien las participaciones de las remuneraciones y el empleo respecto del total de remuneraciones pagadas y del personal ocupado a nivel nacional han crecido 6.5 y 5.7 veces respectivamente entre 1980 y 2003, representan en este último año, en el caso de las remuneraciones un poco menos de $4.2 \%$ del total nacional y menos de $3.4 \%$ del total del personal ocupado.

El tema de la articulación de la industria maquiladora con la economía nacional exige el análisis pormenorizado de sus principales componentes. En orden de importancia, primero los insumos importados, seguidos de los insumos nacionales y gastos diversos pagados localmente (en particular servicios y alquileres), las remuneraciones y prestaciones pagadas y, por último, las utilidades reportadas por la actividad. En términos agregados, también pueden descomponerse en dos grupos: insumos importados y los componentes 
Cuadro 3

Evolución de los componentes de la producción en la maquila de exportación 1980-2003 Porcentaje $(\%)$ del valor bruto de la producción anual

\begin{tabular}{|c|c|c|c|c|c|}
\hline \multirow[b]{2}{*}{$A \tilde{n} o$} & \multirow{2}{*}{$\begin{array}{l}\text { Insumos } \\
\text { importados }\end{array}$} & \multirow{2}{*}{$\begin{array}{c}\text { Insumos } \\
\text { nacionales } y \\
\text { gastos diversos }^{1,2}\end{array}$} & \multicolumn{2}{|c|}{ Valor agregado } & \multirow{2}{*}{$\begin{array}{l}\text { Insumos nacionales } \\
\text { y valor agregado }\end{array}$} \\
\hline & & & y prestaciones & Utilidades & \\
\hline 1980 & 69.35 & 12.49 & 18.16 & n.d. & 30.65 \\
\hline 1981 & 69.55 & 11.81 & 18.64 & n.d. & 30.45 \\
\hline 1982 & 69.85 & 14.76 & 15.38 & n.d. & 30.15 \\
\hline 1983 & 77.53 & 11.73 & 10.73 & n.d. & 22.47 \\
\hline 1984 & 76.45 & 11.32 & 12.24 & n.d. & 23.55 \\
\hline 1985 & 75.12 & 12.06 & 12.82 & n.d. & 24.88 \\
\hline 1986 & 77.06 & 12.48 & 10.45 & n.d. & 22.94 \\
\hline 1987 & 77.51 & 11.92 & 10.58 & n.d. & 22.49 \\
\hline 1988 & 76.96 & 11.89 & 11.15 & n.d. & 23.04 \\
\hline 1989 & 75.66 & 12.01 & 12.33 & n.d. & 24.34 \\
\hline 1990 & 74.40 & 8.18 & 13.24 & 4.17 & 25.60 \\
\hline 1991 & 74.41 & 8.46 & 12.54 & 4.60 & 25.59 \\
\hline 1992 & 74.61 & 8.02 & 14.07 & 3.30 & 25.39 \\
\hline 1993 & 75.24 & 7.84 & 13.68 & 3.23 & 24.76 \\
\hline 1994 & 77.91 & 6.82 & 12.53 & 2.74 & 22.09 \\
\hline 1995 & 84.17 & 5.51 & 8.02 & 2.30 & 15.83 \\
\hline 1996 & 82.62 & 6.61 & 8.51 & 2.26 & 17.38 \\
\hline 1997 & 80.44 & 7.24 & 9.84 & 2.48 & 19.56 \\
\hline 1998 & 80.17 & 7.47 & 9.64 & 2.72 & 19.83 \\
\hline 1999 & 78.94 & 7.87 & 10.24 & 2.95 & 21.06 \\
\hline 2000 & 77.65 & 8.51 & 11.34 & 2.50 & 22.35 \\
\hline 2001 & 74.92 & 9.49 & 12.58 & 3.01 & 25.08 \\
\hline 2002 & 75.93 & 9.37 & 11.65 & 3.06 & 24.07 \\
\hline 2003 & 76.24 & 9.68 & 10.93 & 3.16 & 23.76 \\
\hline $2004 *$ & 77.91 & 8.48 & 10.71 & 2.90 & 22.09 \\
\hline
\end{tabular}

${ }^{1}$ Todos los componentes del valor bruto de la producción se dividen entre las exportaciones de la maquila por el tipo de cambio promedio compra-venta.

${ }^{2}$ Los insumos nacionales y gastos diversos incluyen las utilidades. n.d.: No disponible.

* Información preliminar.

Fuente: elaboración propia con base en INEGI y Nacional Financiera, s.N.C., La economía mexicana en cifras 1995 , México, 1996.

nacionales: insumos locales y valor agregado. Por el momento, en el Cuadro 3, sólo nos interesa destacar que los insumos importados han representado en el periodo analizado entre 69.3 y $84.2 \%$ del total del valor de las exportaciones de la industria maquiladora; mientras que los componentes nacionales, insumos locales y valor agregado, han fluctuado entre 30.7 y $15.8 \%$ del total del valor de las exportaciones.

En la Gráfica 1 se presentan algunos de los parámetros estructurales que serán utilizados cuando se analice la contribución de la industria maquiladora al crecimiento económico. Al respecto, destacan la propensión a importar insumos de la industria maquiladora, el componente importado de la formación bruta de capital, la participación de las 


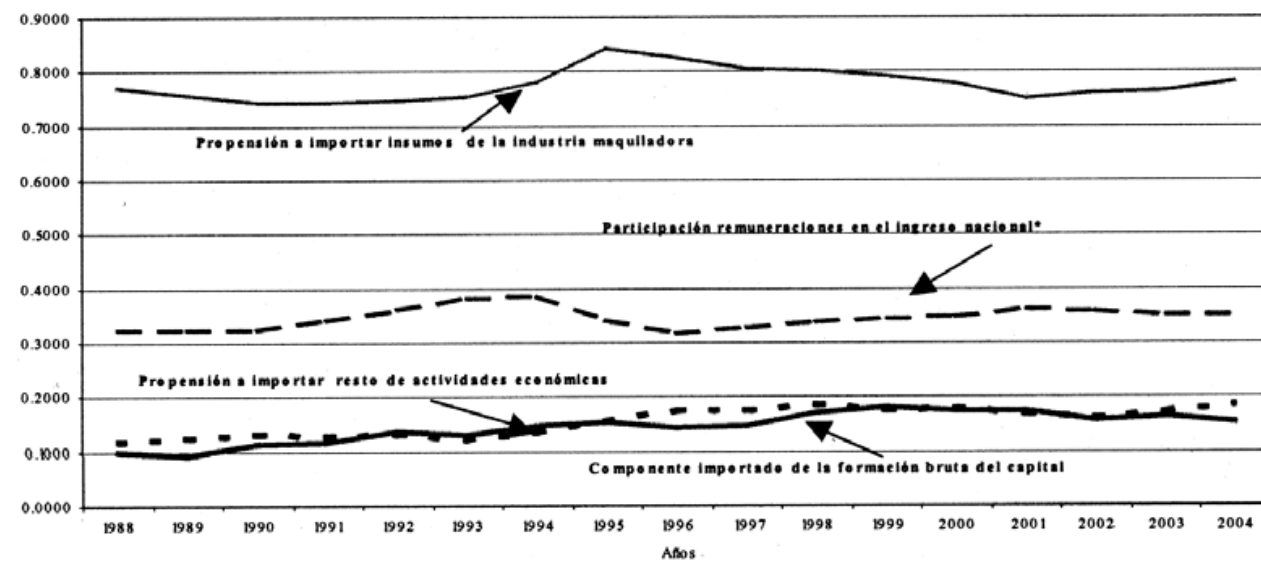

Gráfica 1. Principales parámetros estructurales de la economía mexicana (\%).

* Se mantiene la participación del 2003.

Fuente: elaboración propia con base en INEGI y Nacional Financiera, S.N.C., La economía mexicana en cifras 1995, México, 1996.

remuneraciones en el ingreso nacional y la propensión a importar del resto de actividades económicas. En todos los casos esos parámetros cambian en el tiempo como resultado de elementos técnicos (naturaleza de los procesos productivos y tecnologías), modificaciones en los precios relativos (evolución de los precios al consumidor, tipo de cambio), factores externos (precios internacionales), su interacción, mayor o menor poder relativo respecto de otros actores (salarios nominales relativos a los precios) y por la implantación de políticas públicas (macroeconómica-fiscal-comercial-cambiaria-monetaria, meso o sectoriales, microeconómicas, ingresos-salarios mínimos, entre otras).

No vamos a realizar un análisis pormenorizado de la evolución de cada uno de esos parámetros, pero es interesante comentar que es posible identificar algunos de los factores explicativos para los momentos en que adquieren sus valores máximos, mínimos o intermedios. El valor máximo de la participación de las remuneraciones en el ingreso nacional se logra en 1993, mientras que como resultado de la crisis en 1994-1995 se produce una caída en los ingresos reales de la población y, por tanto, de su participación en el ingreso-producto nacional. En razón inversa, la mayor propensión a importar insumos de la industria maquiladora se ubica en 1995 como resultado de la menor participación de los insumos nacionales y valor agregado de la industria maquiladora producto de la significativa depreciación del peso mexicano, que reduce la participación de estos dos componentes. Tanto el componente importado de la formación bruta de capital como la

22 Lamentablemente no se cuenta con la información homogénea para el caso de la participación de las remuneraciones en el ingreso nacional para el periodo 1980 1987, razón por la cual no presentamos toda la información correspondiente al periodo 1980 2003. 
Cuadro 4

Regresiones seleccionadas entre el PIB y las exportaciones en el nivel internacional, 1990-2003

\begin{tabular}{|c|c|c|c|c|c|c|}
\hline Variables endógenas & $\begin{array}{l}\begin{array}{ll}V \quad a \quad r \\
\text { Constante }\end{array} \\
\text { C }\end{array}$ & $\begin{array}{ccccc}i & a & b & l & e \\
\text { Variación absoluta } & \\
\text { de las exportaciones }\end{array}$ & $\begin{array}{l}s \quad \begin{array}{l}s \\
\text { Dummy } \\
\text { EUA }\end{array} \\
\text { D }\end{array}$ & $\begin{array}{llll}p & l & i & c \\
& & & \\
& & \\
& R^{2} & \end{array}$ & $\begin{array}{lll}a \quad t \quad i \quad & \\
& p \\
\text { Prueba } F & \end{array}$ & 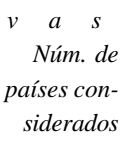 \\
\hline $\begin{array}{l}\text { Variación absoluta del PIB } \\
\text { (miles de millones de dólares) }\end{array}$ & $\begin{array}{l}-30.62613 \\
(-1.153296)\end{array}$ & $\begin{array}{r}3.730074 \\
(10.00233)\end{array}$ & & 0.450566 & 100.0466 & 124 \\
\hline $\begin{array}{l}\text { Variación absoluta del PIB } \\
\text { (miles de millones de dólares) }\end{array}$ & $\begin{array}{c}-0.487071 \\
(-0.073288)\end{array}$ & $\begin{array}{c}1.886014 \\
(18.44674)\end{array}$ & $\begin{array}{l}3,169.491 \\
\quad(42.99642)\end{array}$ & 0.966248 & $1,731.973$ & 124 \\
\hline $\begin{array}{l}\text { Variación absoluta del PIB } \\
\text { (miles de millones de dólares) }\end{array}$ & & $\begin{array}{c}1.882813 \\
(20.45044)\end{array}$ & $\begin{array}{l}3,170.061 \\
\quad(43.42273)\end{array}$ & 0.966246 & $3,492.417$ & 124 \\
\hline
\end{tabular}

Nota: los valores debajo de los parámetros de las regresiones corresponden a la prueba $t$.

Fuente: elaboración propia con base en Banco Mundial, World Development Indicators 2005, CD.

propensión a importar de las otras actividades económicas tienen una tendencia creciente como resultado de la apertura comercial iniciada desde mediados de los años ochenta. ${ }^{22}$

Es importante destacar que no proponemos que sea una cuestión sencilla la modificación de algunos de los parámetros estructurales mencionados anteriormente, ya que en algunos, como son, por ejemplo, la participación de los sueldos y salarios en el ingreso nacional, confluyen elementos explicativos exógenos que reflejan la estructura productiva, de política como los salarios mínimos.

\section{Contribución del sector exportador al desempeño económico: evidencia internacional}

Con independencia del enfoque teórico, es evidente que el desempeño del sector exportador contribuye al crecimiento del producto interno bruto. Al respecto, con base en la información del Banco Mundial ${ }^{23}$ se evalúa la contribución de la variación absoluta de las exportaciones reales a la variación del producto real entre 1990 y 2003 para 124 países en los que existe toda la información estadística.

Las mejores regresiones lineales se muestran en el Cuadro 4, en el cual se observa en todos los casos un crecimiento de las exportaciones que genera una expansión positiva en el producto, aunque el parámetro de vinculación entre ambas variables sea diferente. En segundo lugar, es necesario señalar que en todas las regresiones los parámetros que vinculan las variables anteriores, en forma individual y conjunta, son significativamente diferentes de cero a $99 \%$ en cuanto a confianza. La bondad de ajuste de las ecuaciones, reflejada en el $R^{2}$ es aceptable, elevándose en los casos en que incorporamos una variable

23 Banco Mundial, World Development Indicators 2005, CD.

\section{DeSarrollo}




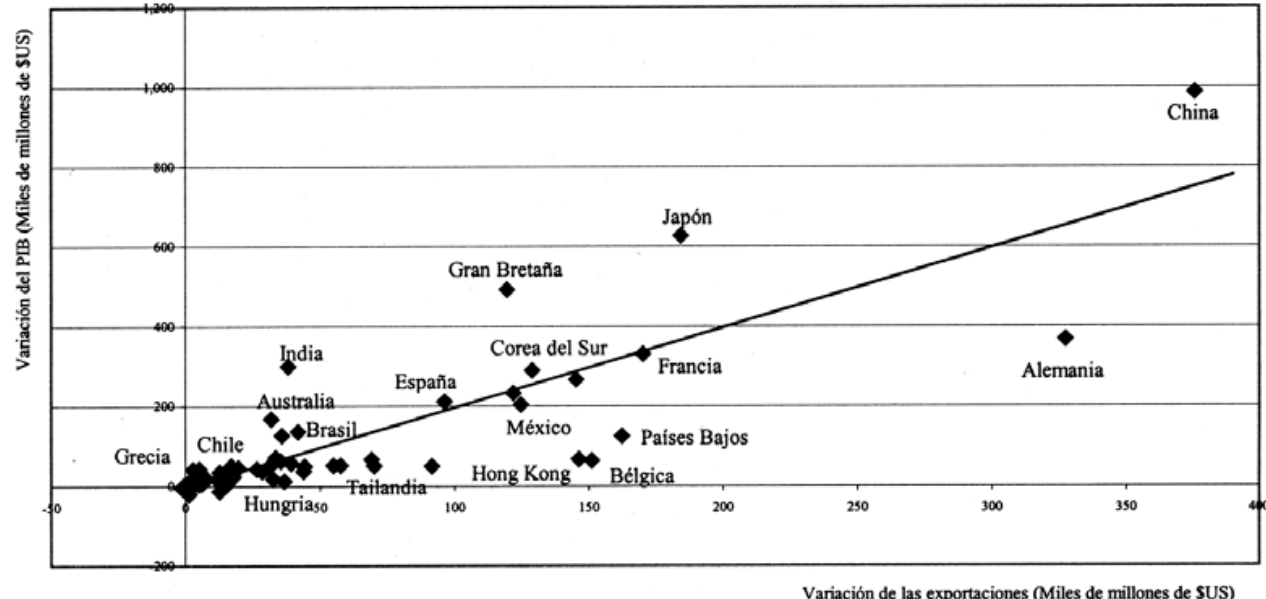

Gráfica 2. Contribución de las exportaciones al producto interno bruto 1990-2003.

Fuente: elaboración propia con base en Banco Mundial, World Development Indicators 2005, CD.

complementaria dummy para Estados Unidos, ya que sus exportaciones crecen en poco más de us $\$ 330$ miles de millones, mientras que su producto lo hace en us $\$ 3792$ miles de millones en el periodo analizado. ${ }^{24}$ Con el tratamiento particular a ese país, el multiplicador de las exportaciones al producto promedio internacional se ubica en 1.9 con una bondad de ajuste cercana a 97\%. Una variación absoluta real de las exportaciones en us\$100 millones, de conformidad a la evidencia empírica internacional, conduciría a un crecimiento del producto real en aproximadamente us 190 millones.

No sólo resulta interesante destacar el valor promedio de la vinculación entre la variación de las exportaciones y del producto, sino los elementos que podrían explicar que un país se ubique por arriba y por abajo de esta relación. Cuando el valor observado de la variación del producto es superior a la estimada por la regresión o las exportaciones tienen en la realidad una mayor contribución al producto, o existen otros factores no comprendidos en la regresión que explican esa mayor variación del producto. Por el contrario, si el valor observado del producto es menor que el estimado por la regresión o las exportaciones generan menores efectos dinamizadores en los eslabonamientos con respecto del producto, o existen otros factores no comprendidos en la regresión que contribuyen a un menor crecimiento del producto. En la Gráfica 2, considerando la segunda ecuación, podemos ubicar algunos países que se encuentran por arriba y por debajo de la tendencia promedio internacional. Entre los países en que las exportaciones, en el periodo analizado, parecerían generar mayores impactos en el producto están Australia, Brasil, China, Corea del Sur,

24 En la medida en que la variación de las exportaciones respecto del producto es muy pequeña, parece revelar que los factores dinamizadores de la economía estadounidense corresponden a otros de la economía interna: inversión, variables monetarias y fiscales, entre otras.

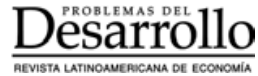


Egipto, Gran Bretaña, Grecia, India, Japón, España, Suiza, y Chile a menor escala. México, a pesar del alto crecimiento en las exportaciones observado entre 1990-2003, se encontraría en el grupo de los países en que las exportaciones muestran menor contribución al producto que el resto de las economías. Las importantes pero desarticuladas exportaciones de la industria maquiladora mexicana pueden ser una de las razones de esa menor contribución al producto. Otros países del grupo son Austria, Bélgica, Hong Kong, República Checa, Alemania, Hungría, Malasia, Países Bajos, Rumania, Arabia Saudita, Singapur, Suecia y Tailandia.

\section{Determinación del potencial de articulación y comparación con otras reformas}

La evaluación de la naturaleza de la articulación de la industria maquiladora con la economía nacional puede realizarse mediante el diseño e implantación de un modelo macroeconómico simple, en el cual el producto mexicano $(Y)$ se define tradicionalmente como la suma de los diferentes componentes de la demanda agregada: consumo privado $(C)$, consumo del gobierno $(G)$ inversión privada y pública, incluyendo la variación de inventarios $(I)$, las exportaciones $(E)$ menos las importaciones $(M)$.

$$
Y=C+G+I+E-M
$$

El consumo privado tendría dos componentes: el consumo de los propietarios de los medios de producción y el de los asalariados.$^{25} \mathrm{El}$ consumo privado de los propietarios e independientes sería equivalente al producto de su propensión a consumir $\left(\gamma_{\mathrm{p}}\right)$ por la participación en el producto-ingreso nacional $(\alpha)$. El consumo de los asalariados sería igual a los ingresos recibidos, gastando todo lo que reciben $\left(\gamma_{A}=1\right)$; de forma tal que su consumo es equivalente a la fracción del producto no recibido por los propietarios de los medios de producción e independientes $(1-\alpha)$.

$$
C=\left[\gamma_{P} \alpha+(1-\alpha)\right] Y
$$

En este modelo simple supondremos que sólo una fracción de la formación bruta de capital se lleva a cabo en bienes de origen nacional (CNI) que activan la demanda y producción local, ya que una fracción de ésta $\left(\theta_{1}\right)$ corresponde a las importaciones de bienes de capital $(M B K)$. Asimismo, las exportaciones son la suma de las realizadas por la

25 A partir de aquí se incorporan los elementos postkeynesianos - kaleckianos relativos a los diferentes grupos sociales, la importancia de la distribución del ingreso en la determinación del nivel de actividad económica, la determinación del producto a partir de la demanda, la existencia de precios fijos y la presencia de parámetros estructurales como las propensiones a importar.

\section{DeSarrollo}


industria maquiladora $(E M)$ y de las otras exportaciones $(O E)$. Las importaciones que realiza la economía mexicana incluyen las importaciones de bienes de capital, tanto de la industria maquiladora, como del resto de la economía, las importaciones de insumos de la industria maquiladora que son una proporción de las exportaciones $\left(\theta_{2}\right)$ y de las otras importaciones de la economía que dependen del nivel de producto-ingreso $\left(\theta_{3}\right)$.

$$
\begin{gathered}
C N I=\left(1-\theta_{1}\right) I \\
E=E M+O E \\
M=M B K+\theta_{2} E M+\theta_{3} Y
\end{gathered}
$$

Reemplazando las ecuaciones (2), (3), (4) y (5) en (1) obtenemos el producto de la economía mexicana como una función directa del componente nacional de la formación bruta de capital, de las exportaciones netas de la industria maquiladora, de las otras exportaciones y del consumo público. Depende igualmente del multiplicador del gasto que incorpora la propensión a consumir de los propietarios de los medios de producción e independientes, de la participación de los ingresos de los propietarios e independientes en el ingreso-producto nacional y de la propensión a importar de los otros sectores de la economía.

Cuando se incrementa el componente nacional de las exportaciones de la maquila se eleva el ingreso-producto nacional, mientras que éste se reduce cuando aumenta la participación de las importaciones de la industria maquiladora. De igual forma, si se eleva el componente nacional de la formación bruta de capital el producto es mayor, mientras que si el componente importado de la inversión es mayor, el producto sería menor. En el caso del multiplicador del gasto, éste es menor si la propensión a importar de los otros sectores económicos es mayor, mientras que es más elevado si la participación de las remuneraciones $(1-\alpha)$ en el ingreso-producto nacional es mayor.

$$
Y=\frac{G+I\left(1-\theta_{1}\right)+E M\left(1-\theta_{2}\right)+O E}{\left[1-\gamma_{P} \alpha-(1-\alpha)+\theta_{3}\right]}
$$

La aplicación de este modelo para el periodo 1988-2003 se realiza considerando la información del INEGI sobre precios corrientes que se convierten a constantes con el deflactor del producto con base en 1993. Para 2004 se supone la misma estructura de la distribución del ingreso de 2003. El ajuste estadístico del modelo a la realidad es casi perfecto, ya que se trata de información histórica. Las exportaciones de la industria maquiladora se consideran inicialmente en us\$, que se convierten a moneda nacional tomando en cuenta el tipo de cambio promedio compra-venta. Las otras exportaciones de bienes y servicios en moneda 
nacional se determinan residualmente como la diferencia de la información de las exportaciones totales de las cuentas nacionales y las exportaciones de la industria maquiladora. En el caso de las importaciones, se realiza un tratamiento homólogo a partir de las asociadas a los insumos de la industria maquiladora y a las de bienes de capital (incluye las importaciones de capital de la industria maquiladora). Las otras importaciones de bienes y servicios en moneda nacional se determinan residualmente.

La determinación de los aspectos distributivos requiere mayor explicación, ya que se parte de la estructura de distribución del ingreso de los componentes principales disponibles en México: remuneración de los asalariados y excedente neto de operación que comprendería los ingresos de los propietarios de los medios de producción y de los ingresos de los independientes. ${ }^{26}$ Se supone que la propensión a consumir de los asalariados es uno, por lo que consumen todo lo que reciben como ingresos, es decir, no ahorran. Por lo anterior, la multiplicación de su participación porcentual en el producto-ingreso nacional por el PIB determinaría el consumo de los asalariados. El consumo de los propietarios de los medios de producción y de los independientes se calcula como la diferencia del consumo privado y el consumo de los asalariados. La propensión a consumir de los propietarios e independientes se calcula a partir del cociente de sus consumos entre el producto-ingreso recibidos. Con todos esos elementos se estima el producto nominal, real y sus tasas de crecimiento que coinciden con las oficiales, razón por la cual resulta innecesaria su presentación. ${ }^{27}$

Un primer ejercicio que realizamos con el modelo fue simular el producto interno bruto real a partir de diferentes propensiones a importar insumos de la industria maquiladora (véase el Cuadro 5). Si la habida en el periodo 2000-2004 hubiera sido menor a la observada, con valores similares a lo ocurrido en 1980, el producto en 2000 y en 2004 hubiera sido $2.2 \%$ superior al observado. Esta dinámica también se presentaría en los otros años, aunque con una menor contribución marginal al producto, debido a que el desempeño de las exportaciones de la industria maquiladora fue menos positiva, como en 2001-2003.

Por el contrario, si la propensión a importar insumos de la industria maquiladora fuese más elevada, tal como ocurrió en 1995 como resultado de los ajustes cambiarios que redujeron la proporción de los componentes nacionales: insumos locales y valor agregado en el valor bruto de la producción, el producto en todos los años simulados sería entre 1.6 y $2.4 \%$ menor al observado. La utilización de las propensiones a importar insumos intermedias de 1985 y 1990, más reducidas que las de 2000, nos conducirían a niveles de

26 Lamentablemente en México no se cuenta con la información relativa a los ingresos de los independientes, que debería captarse directamente o estimarse a partir de los censos económicos, como se realiza en otros países.

27 En el caso de 2004, al suponer la estructura de distribución del ingreso nacional de 2003, se busca obtener el producto real y tasas de crecimiento real oficiales determinando residualmente el deflactor del producto. La diferencia a este respecto del oficial es mínima.

\section{Dêsarreriollo}


Cuadro 5

PIB estimado 2000-2004 con modificaciones en la propensión a importar de la industria maquiladora (millones de pesos de 1993)

\begin{tabular}{lcccccc}
\hline \multirow{2}{*}{ Años } & PIB estimado & PIB propensión & PIB propensión PIB propensión & PIB propensión & PIB propensión \\
& base & 1980 & 1985 & 1990 & 1995 & 2000 \\
\hline 2000 & 1602640 & 1638249 & 1613497 & 1616614 & 1574691 & 1602640 \\
2001 & 1602710 & 1626024 & 1601860 & 1604902 & 1563974 & 1591260 \\
2002 & 1613205 & 1640251 & 1616507 & 1619496 & 1579280 & 1606091 \\
2003 & 1633080 & 1661889 & 1637736 & 1640777 & 1599869 & 1627142 \\
2004 & 1704282 & 1741665 & 1716451 & 1719625 & 1676921 & 1705391 \\
\hline
\end{tabular}

Fuente: elaboración propia a partir de INEGI y Nacional Financiera, s.N.C., La economía mexicana en cifras 1995, México, 1996.

Cuadro 6

Producto y empleo marginal 2000-2004 con propensiones a importar 1980 y 1990 (millones de pesos corrientes y número de trabajadores)

\begin{tabular}{lrcrr}
\hline & \multicolumn{2}{c}{ Propensión a importar 1980 } & Propensión a importar 1990 \\
Años & PIB & Empleos directos & \multicolumn{1}{c}{ PIB } & Empleos directos \\
\hline 2000 & 121990 & 711043 & 47873 & 279037 \\
2001 & 84532 & 463092 & 7948 & 43541 \\
2002 & 104870 & 528304 & 24393 & 122885 \\
2003 & 119114 & 547729 & 31832 & 146338 \\
2004 & 167487 & 692974 & 68741 & 284415 \\
\hline
\end{tabular}

Nota: los empleos directos se estiman como el producto del PIB marginal por la relación empleo remunerado/ PIB proporcionada por el INEGI. En el caso de 2004, se considera una relación de 4.1375, $20 \%$ inferior a la de 2003.

Fuente: elaboración propia a partir de INEGI y Nacional Financiera, s.N.C., La economía mexicana en cifras 1995, México, 1996.

producto real más altos que los observados. Con lo anterior, queda clara la importancia de esta variable en cuanto a su contribución al producto interno bruto real de la economía.

Las modificaciones virtuales ante diferentes escenarios de la propensión a importar insumos de la industria maquiladora mostrados en el Cuadro 5 parecen de menor importancia. Sin embargo, éstas son mayores cuando las expresamos en términos del crecimiento del producto interno bruto nominal y de los empleos generados en los diferentes escenarios simulados. ${ }^{28}$ En el Cuadro 6, considerando las propensiones a importar insumos de la industria maquiladora de 1980 y la intermedia de 1990, se generarían empleos adicionales entre 40 y poco más de 700 mil puestos de trabajo. Con la propensión a importar insumos de 1990 fluctuarían entre 40 y 285 mil empleos (en este último año equivalentes a poco menos de $0.9 \%$ de la fuerza de trabajo ocupada total nacional en 2003). La modificación

28 Se consideran las relaciones empleo/producto observadas en cada año. 
Cuadro 7

Análisis de sensibilidad del crecimiento en el PIB 2004 (variación \% respecto del nivel observado)

\begin{tabular}{|c|c|c|c|c|c|c|c|}
\hline & & $\begin{array}{l}\text { Propensión } \\
\text { Valores } \\
2004\end{array}$ & $\begin{array}{l}a \text { import } \\
\text { Valores } \\
1980\end{array}$ & $\begin{array}{c}\text { insumos } \\
\text { Valores } \\
1985\end{array}$ & $\begin{array}{c}\text { de la ind } \\
\text { Valores } \\
1990\end{array}$ & $\begin{array}{c}\text { ia maqui } \\
\text { Valores } \\
1995\end{array}$ & $\begin{array}{l}\text { adora } \\
\text { Valores } \\
2000\end{array}$ \\
\hline \multirow{6}{*}{$\begin{array}{l}\text { Componente } \\
\text { importado de } \\
\text { la formación } \\
\text { bruta de capital }\end{array}$} & Valores 2004 & 0 & 2.19 & 0.71 & 0.90 & -1.61 & 0.07 \\
\hline & Valores 1980 & 2.76 & 4.96 & 3.48 & 3.66 & 1.16 & 2.83 \\
\hline & Valores 1985 & 3.07 & 5.26 & 3.78 & 3.97 & 1.46 & 3.13 \\
\hline & Valores 1990 & 1.82 & 4.02 & 2.54 & 2.72 & 0.22 & 1.89 \\
\hline & Valores 1995 & 0.01 & 2.20 & 0.72 & 0.91 & -1.60 & 0.08 \\
\hline & Valores 2000 & -0.94 & 1.25 & -0.23 & -0.04 & -2.54 & -0.87 \\
\hline
\end{tabular}

Fuente: elaboración propia a partir de INEGI y Nacional Financiera, s.N.C., La economía mexicana en cifras 1995, México, 1996.

de la propensión a importar insumos de la industria maquiladora tiene impactos significativos en la generación del valor agregado y el empleo.

Los estimados en términos de generación de empleo de nuestros escenarios de simulación se realizan con la información del personal remunerado total del INEGI para los años 20002004, determinando la razón de empleos generados por millón de pesos del pIB para cada año. Luego, de acuerdo con los ejercicios planteados, se determinaron los nuevos niveles de actividad económica, el producto y los empleos marginales que se generarían de mantener las relaciones empleo-producto existentes.

Un segundo ejercicio consiste en simular no sólo las modificaciones en la propensión a importar insumos de la industria maquiladora, sino cambios en otro parámetro estructural como es el componente importado de la formación bruta de capital (FBK). En este caso se evalúa qué ocurriría con el crecimiento del producto interno bruto real entre 2003 y 2004 ante diferentes escenarios en ambas variables. Al igual que en el ejercicio anterior, se consideran años específicos para el valor del componente importado de la formación bruta de capital: 1980, 1985, 1990 y 1995, que son menores a los observados en 2000. Al respecto, si se consideran ambas variables con valores similares a los observados en 1980, el producto real en 2004 habría crecido 5 puntos porcentuales más sobre lo observado (véase Cuadro 7). Lo anterior, por la mayor participación de los insumos nacionales y valor agregado de la producción maquiladora y el mayor componente nacional de la inversión en esos años respecto de los valores observados en 2004.

Obviamente, al asumir la propensión a importar y el componente importado de la formación bruta de capital de 1995, resultaría un menor nivel de actividad económica que el observado, por las mayores filtraciones de la demanda agregada hacia el exterior, tanto por el lado de las importaciones de insumos de la industria maquiladora como por las mayores importaciones de bienes de capital. 
Cuadro 8

Contribución de las políticas estructurales al producto interno bruto (var \%)

\begin{tabular}{|c|c|c|c|}
\hline \multirow[t]{2}{*}{ Escenarios hipotéticos } & \multicolumn{3}{|c|}{$\begin{array}{l}\text { Crecimiento de exportaciones } \\
\text { de la industria maquiladora }\end{array}$} \\
\hline & $5 \%$ & $7.5 \%$ & $10 \%$ \\
\hline Crecimiento del PIB 2005 & 0.28 & 0.43 & 0.57 \\
\hline $\begin{array}{l}\text { Crecimiento del PIB con: } \\
\quad \text { * Propensión a importar insumos maquila } 1990\end{array}$ & 0.33 & 0.49 & 0.66 \\
\hline $\begin{array}{l}\text { Crecimiento del PIB con: } \\
\quad \text { * Propensión a importar insumos maquila } 1990 \\
\text { * Componente importado }\end{array}$ & 138 & 154 & 1.71 \\
\hline $\begin{array}{l}\text { Crecimiento del PIB con: } \\
\text { * Propensión a importar insumos maquila } 1990 \\
\text { * Componente importado FBK } 1993 \\
\text { * Propensión a importar economía } 2002\end{array}$ & 1.44 & 1.61 & 1.79 \\
\hline $\begin{array}{l}\text { Crecimiento del PIB con: } \\
\text { * Propensión a importar insumos maquila } 1990 \\
\text { * Componente importado FBK } 1993 \\
\text { * Propensión a importar economía } 2002 \\
\text { * Estructura distribución del ingreso } 1993\end{array}$ & 1.49 & 1.66 & 1.84 \\
\hline
\end{tabular}

Fuente: elaboración propia con base en INEGI y Nacional Financiera, s.N.C., La economía mexicana en cifras 1995, México, 1996.

La situación se hubiera tornado más negativa si a la propensión a importar insumos de la industria maquiladora de 1995 se agregara el mayor componente importado de la formación bruta de capital de 2000, que habría generado una caída del producto de $2.5 \%$ en 2004. Por otra parte, debemos señalar que en algunos casos los resultados sobre el producto tenderían a contrarrestarse entre sí, ya que una variable podría ocasionar resultados positivos en el producto, mientras que con la otra serían negativos o viceversa. Por ejemplo, esto ocurre cuando se considera la propensión a importar insumos de la industria maquiladora de 1995, pero el componente importado de la formación bruta de capital corresponde a los niveles de 1990.

El impacto del crecimiento exclusivo de las exportaciones de la industria maquiladora en el crecimiento del producto interno bruto real de la economía no es muy significativo, si se considera su aportación actual a las exportaciones, producto, remuneraciones y empleo total. En el Cuadro 8 se observa cómo un aumento de las exportaciones de 5\% generaría en 2005 uno de poco menos $0.3 \%$ en el producto, mientras que uno de $10 \%$ implicaría una expansión del producto real de poco menos de $0.6 \%$, como resultado de los reducidos insumos nacionales y valor agregado de esta actividad. En la medida que el incremento de las exportaciones de la industria maquiladora se acompañe con otras políticas que modifiquen algunos de los parámetros estructurales de la actividad y la economía, esta tendría mayores impactos positivos en la economía en su conjunto. De igual forma, un decrecimiento en 
las exportaciones de dicha industria pudiera ser compensado, en cuanto a su contribución al producto, por medio de la mejora en algunos de estos parámetros estructurales de la actividad y la economía.

El modelo nos permite considerar cuatro parámetros estructurales: propensión a importar insumos de la industria maquiladora, componente importado de la formación bruta de capital, propensión a importar del resto de actividades económicas y estructura de la distribución del ingreso nacional. En todos los casos se asumirían valores hipotéticos similares a los históricos, medianamente positivos-intermedios ${ }^{29}$ y que no son los mejores del periodo analizado. En el Cuadro 8 se observa que cada uno de éstos implicaría una contribución positiva al crecimiento del producto, siendo el más importante la reducción del componente importado de la formación bruta de capital y de la estructura de distribución del ingreso (mayor participación de las remuneraciones en el ingreso-producto nacional) a niveles de 1993.

En conjunto, la modificación de esos parámetros estructurales podría —a niveles de 1993 - generar que el impacto de la expansión de las exportaciones de la industria maquiladora en el crecimiento del producto real se triplique, cuando éstas crezcan 10\%, al pasar de $0.6 \%$ a $1.8 \%$ del PIB. Potenciar la contribución de la industria maquiladora a la economía nacional serviría para mejorar el valor de dichos parámetros: aumentar los insumos nacionales y al valor agregado de la producción maquiladora, elevar el componente nacional de la formación bruta de capital, reducir la propensión a importar del resto de la economía y elevar la participación de las remuneraciones en el ingreso-producto nacional. Se reitera que la modificación real de esos parámetros no es tan simple como la manipulación en un modelo.

No vamos a realizar un análisis pormenorizado de las denominadas propuestas de reformas estructurales formuladas por el poder ejecutivo, pero es claro que de éstas, la energética es la que pudiera tener mayores efectos en la inversión productiva y, por ende, en el crecimiento económico. La reforma fiscal pretendía elevar los ingresos fiscales generalizando el $\mathrm{IVA}^{30} \mathrm{y}$ reduciendo en la medida de lo posible los impuestos directos como el ISR. Al respecto, los mayores ingresos tributarios serían equivalentes a más filtraciones (salidas) de ingresos del sector privado que reducen el nivel demanda-producción, el cual podría ser contrarrestado como resultado de las inyecciones de recursos (mayor gasto público). Por lo anterior, el resultado en el crecimiento económico sería incierto.

La propuesta de reforma laboral, nunca oficialmente detallada por el gobierno, consistía, al parecer, en la flexibilización de las relaciones laborales con miras a elevar la productividad y las inversiones en el país. Ornelas ${ }^{31}$ señala que dicha propuesta pretendía reducir los

29 Probablemente alcanzables con mayor o menor grado de dificultad.

30 J. Ornelas, "Las reformas estructurales", en Economía Informa, núm. 331, Facultad de Economía, México, UNAM, noviembre -diciembre de 2004, p. 10.

31 Ibidem, p. 11.

\section{DeSarrollo}


derechos laborales de los trabajadores, con el fin de ofrecer señales positivas al capital, alentando la inversión a costa de los trabajadores. En esa dirección, el Banco de México proponía eliminar el sistema actual de pagos por despido, la negociación colectiva y los contratos obligatorios para la industria, los requisitos de promociones basados en antigüedad, las restricciones a los contratos temporales, la repartición obligatoria de utilidades, entre otras. Los efectos en el crecimiento económico serían muy inciertos, en la medida que, si bien esas iniciativas tienden a mejorar los rendimientos para los inversionistas, reducen el nivel de ingresos de los trabajadores y, por tanto, el consumo y la demanda en la economía, lo que desalienta futuras inversiones.

La propuesta de reforma energética consistía en promover mayor participación del capital privado en la generación eléctrica, en la extracción de gas natural no asociado, en la construcción y operación de refinerías de petróleo crudo y en la industria petroquímica. Sólo existe información más detallada en relación con el programa eléctrico 2004-2013, en el cual se prevé una inversión total para la década de 592983 millones de pesos, ${ }^{32}$ con un promedio anual de entre 45972 y 67340 millones de pesos. No sólo se calcula que el monto de ese programa está sobreestimado, ${ }^{33}$ sino que tiene un elevado componente importado, ya que, por ejemplo, $72.9 \%$ de la inversión de una planta generadora de electricidad de ciclo combinado de gas natural se realiza en equipos importados. En una planta térmica convencional el citado componente es de $28.3 \%$ y en una carboeléctrica es de alrededor de $43.3 \%{ }^{34}$ Por otra parte, para poder evaluar los efectos hipotéticos de la implantación de esta reforma, habría que dimensionar las inversiones marginales que resultarían de su aplicación, no sus montos absolutos.

En el Cuadro 9 se observa qué incrementos marginales de la inversión implicaría un aumento de la inversión. Si éste es de 1000 millones us\$, el crecimiento económico es del orden de 0.25 puntos porcentuales del PIB en 2005; si la inversión crece en us $\$ 3000$ millones, el incremento del producto es de 0.75 puntos porcentuales, y cuando es de us $\$ 5000$ millones, de 1.25 puntos porcentuales con los parámetros estructurales de la economía mexicana observados en 2004. Si el componente importado de la formación bruta de capital es menor (similar a 1993), los efectos en el crecimiento económico son ligeramente superiores. Es importante comentar que aún en este último caso, el impacto en el crecimiento económico sería menor al que se generaría cuando las exportaciones de la industria maquiladora crecieran sólo a 5\% anual, pero se incorporen todas las políticas en los parámetros estructurales que permitan mejorar su integración con la economía nacional.

32 Secretaría de Energía, Prospectiva del sector eléctrico 2004 2013, México, Sener, 2004.

33 G. Alarco, Inversión necesaria para la reducción de emisiones con crecimiento y redistribución del ingreso 2005 2015, presentación en el Taller de Modelación Económica y Ambiental México Estados Unidos, 11 12 de julio de 2005.

34 Comisión Federal de Electricidad, Costos y parámetros de referencia para la formulación de proyectos de inversión en el sector eléctrico, Generación 2003, México, CFE, 2003. 


\section{Cuadro 9}

Evaluación de impactos de modificaciones marginales en la formación bruta de capital sobre el PIB (var \%)

\begin{tabular}{ccc}
\hline & $\begin{array}{c}\text { Contribución } \\
\text { Parámetrosestructurales }\end{array}$ & $\begin{array}{c}\text { PIB en } \\
\text { Parámetros estructurales 2004 } \\
\text { con componente importado FBK 1993 }\end{array}$ \\
\hline US\$ 1 000 millones & 2004 & 0.26 \\
US\$ 2 000 millones & 0.25 & 0.51 \\
US\$ 3 000 millones & 0.5 & 0.77 \\
US\$ 4 000 millones & 0.75 & 1.03 \\
US\$ 5 000 millones & 1.0 & 1.28 \\
\hline
\end{tabular}

Fuente: elaboración propia con base en INEGI y Nacional Financiera, s.N.C., La economía mexicana en cifras 1995, México, 1996.

Es obvio que si no se modifican los parámetros estructurales, la mayor exportación de la industria maquiladora sería, en cuanto a su contribución al crecimiento económico, sólo ligeramente superior a una inversión adicional equivalente a us\$ 1000 millones anuales.

Un crecimiento moderado en las exportaciones de la industria maquiladora $(7.5 \%$ anual), con la mejora en los parámetros estructurales, hasta alcanzar los niveles históricos seleccionados, podría tener un impacto en el crecimiento del producto bruto interno real superior al que ocurriría si estas reformas generaran inversiones adicionales de alrededor de los us $\$ 5000$ millones anuales. La industria maquiladora incorpora un gran potencial por aprovechar que puede ser superior al que podría generar la denominada reforma energética, la más significativa dentro del conjunto de reformas estructurales propuestas por el gobierno actual.

\section{Esbozo de políticas para mejorar la articulación productiva}

Es claro que la mayor integración del componente nacional y del valor agregado de la industria maquiladora debe ser un objetivo prioritario. Sin embargo, en dirección a lo planteado por Dussel, ${ }^{35}$ se trataría de dejar de soñar en abstracto. Según ese investigador, las propuestas académicas o de política económica que busquen aumentar el valor agregado o la subcontratación local en esos procesos, sin una profunda investigación regional-sectorial sobre los procesos mundiales y territoriales en la cadena de valor agregado, de estudios de costo-beneficio, de propuestas del sector público sin incentivos apropiados, resultan banales y fuera de lugar. No se puede buscar aumentar por decreto el nivel de valor agregado nacional si no se generan incentivos superiores a los existentes. Se debe promover que las

35 E. Dussel, "Ser maquila o no ser maquila, es ésa la pregunta?", en Comercio Exterior, vol. 53, núm. 4, México, BANCOMEXT, abril de 2003.

\section{DeSarrollo}


empresas maquiladoras y otras ${ }^{36}$ realicen esas actividades de manera creciente. Las implicaciones macroeconómicas positivas de hacerlo son evidentes de acuerdo con los resultados presentados en la sección anterior de este documento.

Esta visión concibe, al igual que Buitelaar, Padilla y Urrutia ${ }^{37}$, que la maquila debiera considerarse como una actividad donde pueden diseñarse e implantarse estrategias para impulsar las capacidades y el desarrollo productivo, y no sólo un medio para generar empleo y divisas. Lo anterior, a pesar de que se inició en nuestros países a partir de una noción de competitividad espuria basada en salarios reales reducidos, subsidios fiscales, acceso preferencial a un mercado determinado o a expensas del ambiente. La necesidad de actuar tiene razones externas e internas. En la primera destaca el acicate que impone el comercio exterior de China a nuestros países y a establecer nuevos mecanismos para que la actividad continúe creciendo en el caso ideal de que se incrementen las remuneraciones en términos reales.

En la esfera interna se trata de que esos sueldos y salarios de la industria maquiladora no sean un límite, por problemas de productividad, al resto de remuneraciones de la economía. ${ }^{38}$ Se debe considerar que un segmento de dicha industria está en su tercera generación, ${ }^{39}$ ya que son intensivas en el uso de tecnología y mano de obra capacitada, con la cual localmente se puede contar con parte de la función del diseño de productos ${ }^{40} \mathrm{y}$ de investigación-desarrollo ${ }^{41} \mathrm{y}$, por ende, son el espacio idóneo en donde se pueden incrementar los componentes nacionales y el valor agregado.

La mayor integración de la industria maquiladora a la economía mexicana se tiene que trabajar tanto a partir del diseño e implantación de estrategias y políticas específicas en esta industria, en particular, como de todo el aparato productivo en su conjunto, para evitar la dicotomía entre empresas orientadas hacia el mercado interno y externo. ${ }^{42}$ Muchos investigadores coinciden en este enfoque de dos frentes, aunque con énfasis diferenciado. ${ }^{43}$ También debe abordarse desde un ámbito nacional y otro regional-local. Se trata de que

36 E. Dussel plantea que se debe ampliar la categoría de análisis al de todas las empresas que realizan im portaciones temporales para importaciones, ya que existe otro $30 \%$ de las exportaciones asociadas a los otros regímenes de importación - producción independientes al estrictamente maquilador (Ibidem, p. 336).

37 R. Buitelaar, R. Padilla y R. Urrutia, op. cit., pp. 134 y 151.

38 En la misma dirección de lo planteado por Fujii y Gaona.

39 J. Gerber y J. Carrillo, "Las maquiladoras de Baja California son competitivas?", en Comercio Exterior, vol. 53, núm. 3, México, BANCOMEXT, marzo de 2003, p. 287.

40 R. Buitelaar, R. Padilla y R. Urrutia, op. cit., p. 147.

41 J. Gerber y J. Carrillo, op. cit., pp.289.

42 Naciones Unidas CEPAL, Informe de la reunión de expertos sobre estrategias y políticas de competitividad industrial en Centroamérica: de la integración externa a la integración interna, Guatemala, CEPAL, 13 de julio de 2000.

43 Dussel señala que parecería tener más sentido y viabilidad socioeconómica y territorial enfocarse en el resto del aparato productivo establecido en México (p. 336), mientras que Villarreal y Ramos de Villarreal plantea trabajar en la promoción de las exportaciones y la sustitución de importaciones, rompiendo el falso dilema de la oposición entre ambas políticas (op. cit., p.781).

\section{DeSarrollo}


todo el aparato productivo sea más competitivo para lograr mayor demanda de la industria maquiladora y para tal efecto es necesario recurrir a una concepción sistémica que involucra cuatro diferentes esferas que tienen una interacción dinámica y compleja: el nivel micro, el de las empresas; el nivel meso o intermedio, correspondiente al Estado y los actores sociales que desarrollan políticas de apoyo específico a nivel sectorial-regional; el nivel macro, y por último el nivel meta, que se estructura con sólidos patrones básicos de organización jurídica, política y económica, suficiente capacidad social de organización e integración, visión y capacidad estratégica ${ }^{44}$ Villarreal y Ramos de Villarreal ${ }^{45}$ establecen seis niveles de análisis considerando la esfera internacional-ubicada en el nivel macroeconómico del anterior esquema - y el sistema político-social e institucional que sería parte del nivel meta.

En una visión más integral, Villarreal y Ramos de Villarreal ${ }^{46}$ señalan que debe promoverse el crecimiento a partir de tres pivotes: el sector exportador, el de sustitución competitiva de importaciones, que permitiría articular las cadenas productivas que se han desintegrado en la última década reduciendo el coeficiente de importaciones y el pivote endógeno, impulsado por industrias como la construcción con amplios encadenamientos hacia atrás y hacia delante e intensiva en empleo, siendo necesario promover una nueva banca de desarrollo especializada en cada uno de los pivotes de la industrialización tridimensional. En una dirección similar, Ruiz Durán ${ }^{47}$ plantea que el reto es recuperar efectivamente los encadenamientos productivos, en particular en aquellos eslabones más débiles, lo que se reflejaría en una reducción del coeficiente de penetración de importaciones y en una dinamización del mercado interno respecto de otras variables de la economía. Al efecto propone el fortalecimiento de las pequeña y mediana empresas por medio de programas y acciones concretas que incluyen el abatimiento del rezago tecnológico de éstas, recuperar encadenamientos, financiamiento y fondos de desarrollo empresarial y modificaciones fiscales que otorguen certidumbre e incentiven la reinversión productiva. ${ }^{48}$

En el campo de las políticas intermedias o del nivel meso destaca el fortalecimiento de las políticas educativas y el mejoramiento de los recursos humanos. Se trataría de extender por región-localidad a nivel nacional los comités de enlace entre el sector educativo, en todos sus niveles e instancias públicas y privadas, con la industria maquiladora para evaluar contenidos y necesidades de capacitación, tal como ya ocurre en Ciudad Juárez. ${ }^{49}$ Asimismo,

44 K. Esser, W. Hillebrand, D. Messner y J. Meyer $\sim$ Stamer, "Competitividad sistémica: un nuevo desafío para las empresas y la política”, en Revista de la CEPAL, núm. 59, Santiago de Chile, CEPAL, agosto de 1996, pp. 39 52.

45 R. Villarreal y R. Ramos de Villarreal, op. cit., pp. 784 786.

46 Ibidem, pp. 781 782.

47 C. Ruiz Durán, "Restructurando la economía nacional: hacia un modelo de producción incluyente", en Economía Informa, núm. 312, México, unaM, noviembre de 2002, unAM, pp. 13.

48 Ibidem, pp.13 22.

49 R. Buitelaar, R. Padilla y R. Urrutia., op. cit., pp. 148.

\section{DeSarrollo}


se tienen que promover más intensamente las relaciones con las instituciones de investigación y desarrollo tecnológico. ${ }^{50} \mathrm{Al}$ respecto, no sólo se trataría de fortalecerlas, sino implantar programas específicos que permitan detectar oportunidades de utilización de insumos nacionales en empresas maquiladoras; evaluar su potencial, contactar y desarrollar las capacidades de las empresas manufactureras locales; apoyarlas técnica y financieramente (mediante recursos y tasas especiales) hasta que logren las certificaciones de calidad que la empresa maquiladora exige: promover la sustitución de insumos importados por nacionales con las empresas maquiladoras en particular, y acompañar en el proceso para hacer frente a las dificultades que surjan en el camino.

La creación de parques industriales de alta tecnología es una experiencia por reproducir, tomando en cuenta los éxitos de Malasia y Brasil. Carrillo y Gomis ${ }^{51}$ comentan que las políticas sectoriales como son el desarrollo de agrupamientos industriales (clusters en los cuales existe sinergia entre productores, centros de investigación y desarrollo, universidades, proveedores y clientes) en distintas regiones mexicanas están apoyando el cambio. Al respecto, se menciona el ejemplo de las maquiladoras electrónicas de Tijuana. ${ }^{52}$ En la concepción de esos autores, se trata de moverse hacia plataformas industriales más sofisticadas que logren emplear mano de obra más calificada, que aprovechen las sinergias de la alta tecnología, innovaciones y centros de investigación y desarrollo, y que generen mayor valor agregado.

Otra política relevante para aumentar la integración del sector maquilador es la mejora de las comunicaciones e infraestructura entre la zona fronteriza norte (donde se localiza la mayor parte de esa actividad) y el interior del país, ${ }^{53}$ aunque otros sugieren la instalación de industrias proveedoras de insumos a la actividad maquiladora en la misma zona. El diseño e implantación de las actividades anteriores, aunados a programas que mejoren los precios, calidad y plazos de entrega de la industria manufacturera convencional podrían mejorar la articulación de la actividad. Existe evidencia de que el valor agregado, los componentes físicos y de servicios, es mucho mayor en las plantas maquiladoras ubicadas en el interior del país que en aquellas situadas en la frontera. En relación con ello, la CEPAL $^{54}$ señala que se logra mayor integración en el caso de la industria maquiladora que se localiza en el Distrito Federal y en el Estado de México que en el resto del país.

Un campo de acción relevante en nivel de las zonas fronterizas consiste en la creación de nuevas estructuras institucionales regionales —o el aprovechamiento de las actuales-

so Ibidem, pp. 151.

51 J. Carrillo y R. Gomis., "Integración Económica y maquiladoras en México: evolución y perspectivas frente al reto de China", en R. Partida y J. Carrillo (coordinadores), Integración regional y globalización: impactos económicos y sindicales, México, USAID Fundación Friedrich Ebert, 2005.

52 C. Quintero, op. cit., pp. 12.

53 CEPAL, op. cit., p. 131.

54 Ibidem., p. 132.

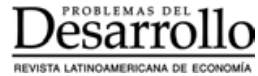


para facilitar la planeación del desarrollo económico de corto, mediano y largo plazos, al ayudar a la identificación de nichos u oportunidades particulares que permitan mayor integración nacional. Otra estrategia útil en el ámbito regional sería la promoción de las prácticas locales de compra a los vendedores y productores sectoriales locales. ${ }^{55}$ Lo anterior, a pesar de que los gerentes de las empresas maquiladoras generalmente carecen de poder de decisión en relación con la adquisición de materias primas, pero pueden opinar acerca de la selección de maquinaria y de la estrategia financiera y de inversión. En cambio, suelen ser íntegramente responsables por la contratación y la capacitación del personal y la organización de la producción. ${ }^{56}$ Todo esto implica una interacción, diálogo intenso y continuo entre las empresas maquiladoras (en gran medida transnacionales) y las diferentes instancias de gobierno. En el caso del resto de las actividades productivas, se sugiere también involucrar a las diferentes Cámaras y asociaciones empresariales ${ }^{57}$ para aprovechar sus experiencias exitosas y su capacidad de convocatoria con el objetivo de lograr mayor integración nacional.

Un elemento que acrecienta los retos de la industria maquiladora es mejorar la articulación productiva interna en el marco de una economía internacional cada vez más globalizada, que ha incrementado los flujos de comercio intraindustrial vertical generados por el desplazamiento de un producto de un país a otro en sus distintas etapas de elaboración, como parte de los modelos de producción compartida tan vigentes en la actividad maquiladora. Sin embargo, no hay que ser pesimista en razón a esta tendencia internacional; las políticas propuestas anteriormente pueden abrir espacios para mayores componentes nacionales y valor agregado. Asimismo, el indicador Grubel-Lloyd calculado para México, que mide esa integración, se estabilizó en niveles altos durante la década de los noventa, aunque se ubica por debajo de los obtenidos para la industria manufacturera sin maquila. ${ }^{58}$

En el campo de lo macroeconómico, no se debe olvidar que la sobrevaluación del tipo de cambio puede constituir un freno a la competitividad, ${ }^{59}$ si no hay incrementos en la productividad. Como referencia, recordemos que en la caída y estancamiento de las exportaciones de la industria maquiladora observada entre octubre de 2000 y diciembre de $2003,{ }^{60}$ en adición a la contracción de la producción industrial de Estados Unidos que explicó 40\% de ésta, el incremento del precio de la mano de obra en dólares estadounidenses por la fuerza relativa del peso mexicano generó entre 25 y $30 \%$ de la pérdida de empleos

55 N. Bringas, A. Díaz Bautista y S. González, "Economía sectorial de la frontera norte", en Economía Informa, núm. 327, México, unAM, junio de 2004, pp. 78.

56 R. Buitelaar, R. Padilla y R. Urrutia, op. cit., pp. 145.

57 Naciones Unidas CEPAL, op. cit., pp. 11.

58 L. Moreno y A. Palerm, "Comercio intraindustrial en el sector manufacturero mexicano", en Comercio Exterior, México, BANCOMEXT, septiembre de 2001, pp. 792.

59 A. Gazol, "Sobre el estancamiento de las exportaciones mexicanas", en Economía Informa, núm. 313, México, UNAM, diciembre de 2002 enero de 2003, pp. 59.

60 J. Carrillo y R. Gomis, op. cit., pp. 31 y 34.

\section{DeSarrollo}


en dicho periodo. ${ }^{61}$ La sobrevaluación del peso no sólo afecta negativamente nuestras exportaciones, sino que promueve mayores importaciones de bienes y servicios. Esto repercute en la industria maquiladora de exportación, que eleva su propensión a importar.

Hemos abordado un conjunto de políticas en los ámbitos macroeconómico, meso o de políticas intermedias y microeconómicas, pero nos faltaría comentar que sin el nivel meta todo este conjunto de políticas podría ser inútil. En dicho nivel, entre otros muchos elementos, debemos mejorar nuestra capacidad estratégica y de gestión, reincorporar el trabajo y esfuerzo en nuestra escala de valores, y administrar mejor nuestros conflictos. La convicción de que se puede lograr mayor integración de la industria maquiladora con la economía nacional es el primer paso para avanzar en el cumplimiento de nuestros objetivos. Se trata luego de pensar, diseñar, discutir, acordar, concertar, implantar y reevaluar. Por último, debemos comentar que esa propuesta de reforma estructural está más a nuestro alcance que las otras, ya que parten de una industria maquiladora real y dinámica. Su impacto positivo en la macroeconomía y en el crecimiento económico de México es evidente.

\section{Bibliografía}

Alarco, G., P. Del Hierro y C. Salas, Reestructuración Productiva: elementos para la acción, Fundación Friedrich Ebert, enero 1992, Lima, 239 pp.

- Inversión necesaria para la reducción de emisiones con crecimiento y redistribución del ingreso 2005-2015, presentación en el Taller de Modelación Económica y Ambiental MéxicoEstados Unidos, 11-12 de julio de 2005. 45 pp.

Alonso, J., J. Carrillo y O. Contreras, Trayectorias tecnológicas en empresas maquiladoras asiáticas $y$ americanas en México, Serie desarrollo productivo 72, CEPAL, agosto de 2000, $52 \mathrm{pp}$.

Bringas, N., A. Díaz-Bautista y S. González, "Economía sectorial de la frontera norte", en Economía Informa, núm. 327, junio de 2004, UNAM, pp. 68-82.

Buitelaar, R., R. Padilla y R. Urrutia, "Industria maquiladora y cambio técnico", en Revista de la CEPAL, núm. 67, abril de 1999, pp. 133-152.

Calderón, C., y R. Ponce, "Demanda de trabajo de la industria maquiladora en Ciudad Juárez", en Comercio Exterior, abril de 2001, pp. 271-278.

Carrillo, J. y R. Gomis, "Los retos de las maquiladoras ante la pérdida de la competi-tividad", en Comercio Exterior, vol. 53, núm. 4, abril de 2003, pp.318-327.

61 J. Gerber y J. Carrillo, op. cit., pp.292.
Carrillo, J. y R. Gomis, “Integración Económica y maquiladoras en México: evolución y perspectivas frente al reto de China", en R. Partida y J. Carrillo (coordinadores), Integración Regional y Globalización: impactos económicos y sindicales, USAID-Fundación Friedrich Ebert, 2005, pp. 31-47.

Comisión Federal de Electricidad, Costos y parámetros de referencia para la formulación de proyectos de inversión en el sector eléctrico, Generación 2003, CFE, 2003.

Dussel, E., "Política de competitividad empresarial y condiciones de la manufactura en México en 2002, cambios con respecto al pasado?", en Economía Informa, núm. 312, noviembre de 2002, UNAM, pp.5-10.

, "Ser maquila o no ser maquila, es ésa la pregunta?", en: Comercio Exterior, vol. 53, núm. 4, abril de 2003, pp. 328-336.

Dussel, E. y L. Xue Dong, "China: competencia comercial con México y Centroamérica", en Comercio Exterior, vol. 55, núm. 3, marzo de 2005, pp. 282-289.

Esser, K., W. Hillebrand, D. Messner y J. MeyerStamer, "Competitividad sistémica: un nuevo

\section{DeSarrollo}


desafío para las empresas y la política”, en Revista de la CEPAL, núm. 59, agosto de 1996, pp. 39-52.

Fujii, G., "Apertura comercial, reforma laboral, empleo y salarios", en Economía Informa, núm. 313 , diciembre de 2002-enero de 2003, UNAM, pp. 31-41.

Fujii, G. y C. Gaona, "El modelo maquilador como barrera al crecimiento del empleo y los salarios en México", en Economía Informa, núm. 323, febrero de 2004, UNAM, pp. 63-71.

Fujii, G., E. Candaudap y C. Gaona, "Salarios, productividad y competitividad de la industria manufacturera mexicana", en Comercio Exterior, vol. 55, núm. 1, enero de 2005, pp. 16-28.

Gazol, A., "Sobre el estancamiento de las exportaciones mexicanas", en Economía Informa, núm. 313 , diciembre de 2002-enero de 2003, UNAM, pp.53-59.

Gerber, J. y J. Carrillo, "Las maquiladoras de Baja California son competitivas?”, en Comercio Exterior, vol. 53, núm. 3, marzo de 2003, pp. 284-293.

León, A. y E. Dussel, "El comercio intraindustrial en México, 1990-1999”, documento inédito, 6 pp.

Mendiola, G., "México: empresas maquiladoras de exportación en los noventa", en Serie Reformas Económicas 49, CEPAL, Diciembre de 1999, 50 pp.

Mendoza, E. y C. Calderón, "Determinantes regionales de la maquila de exportación en la frontera norte", en Comercio Exterior, marzo de 2001, pp. 196-202.

Moreno, L. y A. Palerm, "Comercio intraindustrial en el sector manufacturero mexicano", en Comercio Exterior, septiembre de 2001, pp. 790-794.
Naciones Unidas-CEPAL, América Latina y el Caribe, Políticas para mejorar la inserción a la economía mundial, Santiago de Chile, 1994, 321 pp.

, Informe de la reunión de expertos sobre estrategias y politicas de competitividad industrial en Centroamérica: de la integración externa a la integración interna, Guatemala, 13 de julio de 2000, 16 pp.

Ornelas, J., "Las reformas estructurales", en Economía Informa, Facultad de Economía, UNAM, núm. 331 noviembre-diciembre de 2004, pp. 5-13.

Puyana, A. y J.A. Romero, "La maquila (fragmentación de los procesos productivos) y su impacto sobre las remuneraciones a los factores", en Problemas del Desarrollo, vol. 36, núm. 141, abril-junio 2005, pp. 155-182.

Quintero, C., "Los claroscuros de la industria maquiladora: los casos de Tijuana y Matamoros", documento El Colegio de la Frontera Norte, Dirección Regional de Matamoros, septiembre de 2003, 32 pp.

Ruiz Durán, C., "Restructurando la economía nacional: hacia un modelo de producción incluyente", en Economía Informa, núm. 312, noviembre de 2002, UNAM, pp. 11-22.

Villarreal, R. y R. Ramos de Villarreal, "La apertura de México y la paradoja de la competitividad: hacia un modelo de competitividad sistémica", en Comercio Exterior, septiembre de 2001, pp. 772-788.

\section{Desarrollo}

